\title{
Health literacy: strengthening agency or changing structures?
}

\author{
Oliver Razum $\cdot$ Heide Weishaar $\cdot$ Doris Schaeffer
}

Received: 5 January 2016/Accepted: 10 January 2016/Published online: 10 February 2016

(c) Swiss School of Public Health (SSPH+) 2016

Health literacy, according to the Nutbeam's definition, comprises "the cognitive and social skills which determine the motivation and ability of individuals to gain access to understand and use information in ways which promote and maintain good health" (Nutbeam 1998). Accordingly, the US Institute of Medicine lists "cultural and conceptual knowledge, listening, speaking, arithmetical, writing, and reading skills" as elements of health literacy (NielsenBohlman et al. 2004). Different skills may be needed depending on the particular context (Dermota et al. 2013; Ackermann Rau et al. 2014). Is health literacy thus a clearly defined and non-controversial issue? Not quite.

Today, responsibility for health is increasingly being shifted from the society to the individual-even to individuals who may not be able to fully embrace such growing obligations. Health literacy is at risk of developing a similar tendency: strengthening health literacy is often seen merely as a solution to increase

\section{O. Razum ( $\square)$}

Department of Epidemiology and International Public Health, School of Public Health, Bielefeld University, P. O. Box 100131, 33501 Bielefeld, Germany

e-mail: oliver.razum@uni-bielefeld.de

\section{H. Weishaar}

MRC/CSO Social and Public Health Sciences Unit, University of Glasgow, 200 Renfield Street, Glasgow G2 3QB, UK e-mail: Heide.Weishaar@glasgow.ac.uk

\section{Schaeffer}

Department of Public Health Nursing and Health Services Research, School of Public Health, Bielefeld University, P. O. Box 100131, 33501 Bielefeld, Germany

e-mail: doris.schaeffer@uni-bielefeld.de compliance in individuals with the final aim of changing behaviour. Greenhalgh (2015), for example, in an otherwise enlightening BMJ editorial, suggests to take "...the perspective of a patient living in a particular set of real world circumstances and ask what is stopping him or her from achieving the best health outcomes in these circumstances". We argue that this approach fails to take account of the challenges inherent in keeping individuals and, in fact, population groups healthy.

Sørensen et al. (2012) see the purpose of health literacy as helping people to make sound health-related decisions. They acknowledge that the ability to interpret and evaluate information relating to health cannot be restricted to medical issues but must extend to health promotion and prevention. Health literacy, they argue, "has the potential to impact on preventative health and reduce pressures on health systems." On the one hand, Sørensen et al.'s work implies a broader perspective on population groups; on the other hand, it could put even more emphasis on the need for structural changes. In times when the crucial role of social determinants of health is increasingly being recognised, effective solutions have to involve tackling inequities and the structures that produce them (Freudenberg and Tsui 2014). This is even more important given continuing corporate efforts to frame the control of health risks, such as smoking or obesity, as personal responsibilities (Dorfman et al. 2014).

Freedman et al. (2009) explicitly extend the concept to "public health literacy" accordingly. Conceptually, they base health literacy on critical skills and civic orientation and situate it within broader aims of resolving society's pressing health issues and alleviating social injustices. In line with Sørensen et al., who acknowledge that the "ability to make informed 
decisions on health determinants" is not enough, Wills (2009) postulates that modern health literacy has to acknowledge that health is a social product, and that maintaining it requires social or political action. Not all policymakers, however, seem to understand that systemlevel interventions (as opposed to educational programmes targeting individuals) are needed to support people with low health literacy scores in achieving better health (Greenhalgh 2015).

We argue: yes, improved communication and information skills are required in the health care system. And individuals, especially those with lower levels of education, need special support to acquire skills for obtaining and understanding health-related information (Ackermann Rau et al. 2014). But health literacy experts also need to appreciate that ill health is not simply caused by bacteria or high cholesterol, and that visits to the doctor or adherence to therapeutic regimen are not the only means to keep healthy. It is their obligation, together with that of public health professionals and policy makers, to tackle structural problems, like changes in welfare systems and the increasingly unequal distribution of wealth. Such structural factors need to be recognised for what they are: crucial determinants of health. In the long run, raising awareness of these factors may help individuals to take responsibility for alleviating social injustice, for example by becoming socially active or reconsidering for whom to vote in the next election (Freudenberg and Tsui 2014). So a careful balance is needed: health literacy initiatives should strengthen agency, but they should not shift the responsibility for structural changes to the individual.

\section{Compliance with ethical standards}

Conflict of interest Oliver Razum declares that he has no conflict of interest. Heide Weishaar declares that she has no conflict of interest. Doris Schaeffer declares that she has no conflict of interest.

\section{References}

Ackermann Rau S, Sakarya S, Abel T (2014) When to see a doctor for common health problems: distribution patterns of functional health literacy across migrant populations in Switzerland. Int $\mathbf{J}$ Public Health 59:967-974. doi:10.1007/s00038-014-0583-5

Dermota P, Wang J, Dey M, Gmel G, Studer J, Mohler-Kuo M (2013) Health literacy and substance use in young Swiss men. Int $\mathbf{J}$ Public Health 58:939-948. doi:10.1007/s00038-013-0487-9

Dorfman L, Cheyne A, Gottlieb MA, Mejia P, Nixon L, Friedman LC, Daynard RA (2014) Cigarettes become a dangerous product: tobacco in the rearview mirror, 1952-1965. Am J Public Health 104:37-46. doi:10.2105/AJPH.2013.301475

Freedman DA, Bess KD, Tucker HA, Boyd DL, Tuchman AM, Wallston KA (2009) Public health literacy defined. Am J Prev Med 36:446-451. doi:10.1016/j.amepre.2009.02.001

Freudenberg N, Tsui E (2014) Evidence, power, and policy change in community-based participatory research. Am J Public Health 104:11-14. doi:10.2105/AJPH.2013.301471

Greenhalgh T (2015) Health literacy: towards system level solutions. BMJ 350:h1026. doi:10.1136/bmj.h1026

Nielsen-Bohlman L, Panzer AM, Kindig DA (2004) Health literacy: a prescription to end confusion. The National Academies Press, Washington, DC

Nutbeam D (1998) Health promotion glossary. Health Promot Int 13:349-364. doi:10.1093/heapro/13.4.349

Sørensen K, Van den Broucke S, Fullam J, Doyle G, Pelikan J, Slonska Z, Brand H (2012) Health literacy and public health: a systematic review and integration of definitions and models. BMC Public Health 12:80

Wills J (2009) Health literacy: new packaging for health education or radical movement? Int J Public Health 54:3-4. doi:10.1007/ s00038-008-8141-7 